\title{
Hysterectomy: Hysteroscopic Sterilization's Unintended Dividend?
}

\author{
E Scott Sills ${ }^{1,2 *}$ \\ ${ }^{1}$ Reproductive Research Division, Center for Advanced Genetics, USA \\ ${ }^{2}$ Department of Obstetrics \& Gynecology, Palomar Medical Center, USA
}

Submission: May 25, 2017; Published: June 15, 2017

*Corresponding author: E Scott Sills, Center for Advanced Genetics, 3144 El Camino Real, Suite \#106, Carlsbad, California 92008, USA, Tel: +1 760-994-0156; Fax: +1 760-994-0159; Email: drsills@CAGivf.com

\section{Abstract}

Although previous work has suggested that the risk for re-operation after hysteroscopic sterilization (HS) is much higher than for patients who undergo standard laparoscopic tubal ligation, few data have been collected on these subsequent procedures. Recently, a descriptive cohort study used a confidential online questionnaire to gather data from more than 3,000 women who developed pelvic pain and other symptoms after HS. Information was obtained on device removal surgery performed secondary to symptoms developing after the Essure

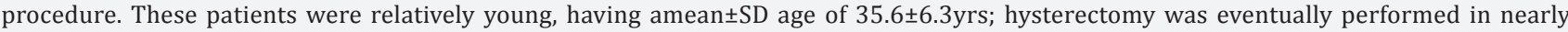
$65 \%$ of HS cases. More research is needed to characterize specific gynecological operations after HS, but preliminary findings suggest that the predominant surgical remedy for Essure-associated complaints is hysterectomy for many women. Thus, dissatisfaction with HS may represent an important new indication for hysterectomy and additional study will be crucial to quantify this phenomenon.

Keywords: Contraception; Pelvic pain; Essure; Hysteroscopic sterilization; Hysterectomy

\section{Background}

The Essure device (Bayer Corp Whippany, NJ USA) gained approval by the U.S. FDA in November 2002 and remains the only hysteroscopic contraceptive method available in the U.S. The procedure can be completed without anesthesia, involves no incision, and may be performed in as a little as ten minutes by an experienced hysteroscopist $[1,2]$. The procedure involves introduces a pair of small, flexible inserts consisting of nickeltitanium and polyethylene terephthalate (PET) fibers through the fallopian tubal ostia via hysteroscopy. Once in place, the devices trigger an intraluminal inflammatory reaction resulting in tubal fibrosis and eventual occlusion. While HS enjoyed considerable initial popularity, within several years complications began to appear in the medical literature and were reported to health regulators [3-6]. Fortunately, surgical removal of HS devices has usually resolved symptoms for most patients $[7,8]$. While there is no consensus on a preferred method to remove Essure implants, hysterectomy has emerged as one way to do this [5,8-10]. The connection between this contraceptive implant and subsequent hysterectomy has only recently been the subject of specific study, however [11].

Hysterectomy is a major operation and is the most frequently performed surgery for women in the United States after cesarean delivery [12]. Accurate data regarding indications for hysterectomy informs a crucial part of monitoring health outcomes. Most estimates of national hysterectomy activity cannot provide a comprehensive assessment because registries are generally limited to surgeries performed in formal hospital settings [13], and hysterectomies are often performed in ambulatory surgery centers outside this data capture remit. A reporting gap also exists with HS, because there is no national registry for this procedure either. Statistical impairments thus exist both for HS and hysterectomy, as reliance on standard hospital reports cannot give a complete audit of either event.

Researchers following hysterectomy have tried to meet this challenge by modifying their study design to follow insurance payments rather than hospital activity [12]. Unfortunately, such an approach does not yield a full understanding of HS, since although this elective sterilization technique is often done on an out-patient basis, it is not uniformly covered by insurance plans in the United States [14-16]. Not even the device manufacturer knows exactly how many patients have had the HS procedure (in the United States or elsewhere) and only data on the approximate number of Essure kits is available [17]. Thus, measuring any common overlap between HS and hysterectomy- 
both gynecological interventions with substantial public health implications-is difficult.

\section{What happens after HS?}

There is no clear consensus on how to manage Essure patients who subsequently develop symptoms after HS [18]. While the notion that these patients might require further surgery is not entirely new, at least for some Essure patients the reliance on hysterectomy can be quite high [11]. One recent analysis evaluated 30-day and 1-year outcomes after $>8,000$ Essure procedures in New York State and found the risk of undergoing reoperation was more than 10 times higher for HS patients compared to patients undergoing standard laparoscopic tubal ligation [19]. Recent work has extended this observation by contributing a more detailed understanding of surgeries performed after Essure [11].

As HS coils are intended to be permanent contraceptive implants, it is not surprising that familiarity with their surgical excision remains limited $[5,8,20]$. It is encouraging that satisfactory relief of Essure-associated symptoms has been reported as soon as two weeks following removal [21]. Why might HS be perceived as better than traditional bilateral tubal ligation? A 2009 decision tree analysis to estimate procedure costs is sometimes cited to support the position that HS brings a cost advantage over standard tubal sterilization [22]. Such a model now seems problematic as it incorrectly assumed that patient satisfaction would be similar between the two comparator groups. Because few patients in HS premarketing studies were followed for more than 12 months [23], how many might seek additional surgery to "undo" Essure after the first year of use could not have been known previously. Although it is not surprising that such extra surgery brings additional expense, some research has shown that a priori costs for HS are already higher than for laparoscopic tubal ligation despite shorter operative time and less frequent use of general anesthesia [19]. Controversy also exists concerning the effectiveness of HS as a method of reliable birth control $[24,25]$. This raises the question of device failure with profound economic and social implications of its own [26]. While none of this information was available for consideration when Essure was initially approved by the U.S. FDA in 2002, awareness of such factors now could explain a higher level of patient interest in surgical device removal.

Likewise, hysterectomy may be regarded (either by physicians, patients, or both) as superior to other less invasive surgical approaches for Essure abatement. For example, it is possible that the lack of a CPT code specific to surgical Essure removal favors hysterectomy, a surgery for which multiple CPT codes exist. Despite the known higher cost, intra operative blood loss, overall complication rate and increased recovery time associated with hysterectomy, this surgery could nevertheless be recommended over less aggressive operations for which insurance companies might reject or delay the claim (i.e., no timely disbursement).

\section{Conclusion}

Interpreting HS data continues to frustrate regulators, patients, and advocacy groups. Thus, until the regulatory climate changes to enable acquisition of HS data with greater precision, internet-based assessment tools may supply the best available evidence on HS. Indeed, similar patient-completed surveys have been used in previous pelvic surgery contexts with good results $[27,28]$. There is also the matter of linking HS to whatever operation which followed, and determining what factors (physician and/or patient) resulted in particular post-HS interventions. Like much of the Essure phenomenon, however, this is an underdeveloped area of inquiry awaiting additional research for clarification. The lack of established clinical guidelines for Essure removal appears to permit a considerable range of surgical approaches in routine practice.

For many women, the allure of "non-incisional" permanent contraception as promised by HS would be substantially diminished if major surgery were later needed $[9,10]$. Given the paucity of meaningful longitudinal data on HS patients, the hysterectomy rate following Essure remains undefined. Yet should this birth control choice even sometimes lead to hysterectomy, caution is appropriate and the issue should receive close scrutiny. If the number of HS kits sold worldwide is 750,000 [23], then determining how these devices contribute to overall hysterectomy uptake represents a relevant topic in the domain of international women's health. Consideration should therefore be given to creating an Essure patient registry, or, alternatively, creating specific ICD-10 codes for patients who present with HS-associated symptoms. These would be costeffective interventions to enable proper surveillance on this topic. References

1. Lee W, Deter R, Sangi-Haghpeykar H, Yeo L, Romero R (2013) Prospective validation of fetal weight estimation using fractional limb volume. Ultrasound Obstet Gynecol 41(2): 198-203.

2. Yang F, Leung KY, Hou YW, Yuan Y, Tang MH (2011) Birth-weight prediction using three-dimensional sonographic fractional thigh volume at term in a Chinese population. Ultrasound Obstet Gynecol 38(4): 425-433.

3. Dudley NJ (2005) A systematic review of the ultrasound estimation of fetal weight. Ultrasound Obstet Gynecol 25(1): 80-89.

4. Moyer-Mileur LJ, Slater H, Thomson JA, Mihalopoulos N, Byrne J, et al. (2009) Newborn adiposity measured by plethysmography is not predicted by late gestation two dimensional ultrasound measures of fetal growth. J Nutr 139(9): 1772-1778.

5. Schild RL (2007) Three-dimensional volumetry and fetal weight measurement. Ultrasound Obstet Gynecol 30(6): 799-803.

6. Lee W, Balasubramaniam M, Deter RL, Yeo L, Hassan SS, et al. (2009) New fetal weight estimation models using fractional limb volume. Ultrasound Obstet Gynecol 34(5): 556-565.

7. Beninni JR, Faro C, Marussi EF, Barini R, Peralta CFA (2010) Fetal thigh volumetry by three-dimensional ultrasound: comparison between multiplanar and VOCAL techniques. Ultrasound Obstet Gynecol 35(4): 417-425.

8. Hur H, Kim YH, Cho HY, Park YW, Won HS, et al. (2015) Feasibility of three-dimensional reconstruction and automated measurement of 
fetal long bones using 5D Long Bone. Obstet Gynecol Sci 58(4): 268276.

9. Hadlock FP, Harrist RB, Sharman RS, Deter RL, Park SK (1985) Estimation of fetal weight with the use of head, body, and femur measurements-a prospective study. Am J Obstet Gynecol 151(3): 333337.

10. Pitman E (1939) A note on normal correlation. Biometrika 31(12): 9-12.

11. Bland JM, Altman DG (2003) Applying the right statistics: analyses of measurements studies. Ultrasound Obstet Gynecol 22(1): 85-93.

12. Melamed N, Yogev Y, Meizner I, Mashiach R, Bardin R, et al. (2009) Sonographic fetal weight estimation: which model should be used? J Ultrasound Med 28(5): 617-629.

13. Orskou J, Kesmodel U, Henriksen TB, Secher NJ (2001) An increasing proportion of infants weigh more than 4000 grams at birth. Acta Obstet Gynecol Scand 80(10): 931-936.
14. Ecker JL, Greenberg JA, Norwitz ER, Nadel AS, Repke JT (1997) Birth weight as a predictor of brachial plexus injury. Obstet Gynecol 90(3): 643-647.

15. Schild RL, Fimmers R, Hansmann M (2000) Fetal weight estimationby three-dimensional ultrasound. Ultrasound Obstet Gynecol 16(5): $4450-4452$

16. Isobe $\mathrm{T}$ (2004) Approach for estimating fetal body weight using two dimensional ultrasound. J Maternal Fetal Neonatal Med 15(4): 225231.

17. Srisantiroj N, Chanprapaph P, Komoltri C (2009) Fractional thigh volume by three-dimensional ultrasonography for birth weight prediction. J Med Assoc Thai 92(12): 1580-1585.

18. Lindell G, Marsal K (2009) Sonographic fetal weight estimation in prolonged pregnancy: comparative study of two- and threedimensional methods. Ultrasound Obstet Gynecol 33(3): 295-300.

19. Benacerraf BR, Shipp TD, Bromley B (2006) Three-dimensional US of the fetus: volume imaging. Radiology 238(3): 988-996.

Your next submission with Juniper Publishers will reach you the below assets

- Quality Editorial service

- Swift Peer Review

- Reprints availability

- E-prints Service

- Manuscript Podcast for convenient understanding

- Global attainment for your research

- Manuscript accessibility in different formats

(Pdf, E-pub, Full Text, Audio)

- Unceasing customer service

Track the below URL for one-step submission https://juniperpublishers.com/online-submission.php 